\title{
Outcome and Early Viral Dynamics with Viral Mutation in PEG-IFN/RBV Therapy for Chronic Hepatitis in Patients with High Viral Loads of Serum HCV RNA Genotype 1b
}

\author{
Noriko Sasase $^{\mathrm{a}}$ Soo Ryang Kim ${ }^{\mathrm{b}}$ Masatoshi Kudo ${ }^{\mathrm{e}} \mathrm{Ke} \mathrm{Ih} \mathrm{Kim}^{\mathrm{a}}$ \\ Miyuki Taniguchi $^{\text {b }}$ Susumu Imoto ${ }^{b}$ Keiji Mita ${ }^{b}$ Yoshitake Hayashic \\ Ikuo Shoji $^{d}$ Ahmed El-Shamy ${ }^{d}$ Hak Hotta ${ }^{d}$ \\ Departments of a Pharmacy and ${ }^{b}$ Gastroenterology, Kobe Asahi Hospital, ' Center for Infectious Diseases and \\ ${ }^{\mathrm{d} D i v i s i o n}$ of Microbiology, Kobe University Graduate School of Medicine, Kobe, and \\ e Department of Gastroenterology and Hepatology, Kinki University School of Medicine, Osaka-Sayama, Japan
}

\section{Key Words}

Chronic hepatitis - Early viral dynamics $\cdot$ IFN/RBV

resistance-determining region $\cdot$ HCV RNA genotype $1 \mathrm{~b} \cdot$

High viral load · PEG-IFN/RBV combination therapy •

Virological response, prediction

\begin{abstract}
We investigated whether sustained virological response (SVR) and non-SVR by chronic hepatitis C patients to pegylated interferon plus ribavirin (PEG-IFN/RBV) combination therapy are distinguishable by viral factors such as the IFN/RBV resistance-determining region (IRRDR) and by on-treatment factors through new indices such as the rebound index (RI). The first RI (RI-1st; the viral load at week 1 divided by the viral load at $24 \mathrm{~h}$ ) and the second RI (RI-2nd; the viral load at week 2 divided by the viral load at $24 \mathrm{~h}$ ) were calculated. The subject patients were divided into 3 groups based on RI-1st and RI-2nd: an RI-A group (RI-1st $\leq 1.0$ ), an RI-B group (RI-1st $>1.0$ and $\mathrm{RI}-2 \mathrm{nd}<0.7)$ and an RI-C group (RI-1st $>1.0$ and $\mathrm{RI}-2$ nd $\geq 0.7)$. The SVR rate was $71.4 \%(10 / 14)$ in the RI-A group,
\end{abstract}

$46.2 \%(6 / 13)$ in the RI-B group and $20.0 \%(3 / 15)$ in the RI-C group ( $p=0.005$ between the RI-A group and the RI-C group). In IRRDR $\geq 6$ and IRRDR $\leq 5$ the SVR rate was $81.3 \%(13 / 16)$ and $23.1 \%(6 / 26)(p=0.0002)$, respectively. By combining $\mathrm{RI}$ and IRRDR as a predicting factor, the SVR rate was $87.5 \%(7 / 8)$ in the RI-A group ( $\geq 6$ mutations in the IRRDR) and $7.7 \%(1 / 13)$ in the RI-C group ( $\leq 5$ IRRDR mutations) ( $p=0.0003$ ).

Copyright $\odot 2010$ S. Karger AG, Basel

\section{Introduction}

Recently, global consensus has obtained that a combination of IFN or pegylated IFN plus ribavirin (PEG-IFN/ $\mathrm{RBV}$ ) is the treatment of choice for chronic hepatitis $\mathrm{C}$ (CHC). Notwithstanding this treatment regimen, sustained virological response (SVR) rates of those infected with the most resistant genotypes [hepatitis $\mathrm{C}$ virus (HCV)-1a and -1b] still hover at $\sim 50 \%[1,2]$. It is therefore worthwhile to identify the predictive factors that allow the selection of patients who would achieve eradication

\section{KARGER}

Fax +41613061234 E-Mail karger@karger.ch www.karger.com
(C) 2010 S. Karger AG, Basel

$0300-5526 / 10 / 0531-0049 \$ 26.00 / 0$

Accessible online at:

www.karger.com/int
Soo Ryang Kim, MD

Department of Gastroenterology

Kobe Asahi Hospital

3-5-25 Bououji-cho, Nagata-ku, Kobe 653-0801 (Japan)

Tel. +81 78612 5151, Fax +81 78612 5152, E-Mail asahi-hp@ arion.ocn.ne.jp 
of HCV RNA either before or during therapy, especially since IFN/RBV combination therapy is costly and has several side effects [3].

Predictors of the effectiveness of IFN-based therapy can be classified into pretreatment and on-treatment factors. Pretreatment factors comprise: (1) host factors such as age, gender, obesity, alcohol consumption, hepatic iron overload, fibrosis, immune responses and co-infection with other viruses, and (2) viral factors that mainly include viral genotypes and loads, particular amino acid sequence variations in the NS5A region $[4,5]$ and in the core protein region of $\mathrm{HCV}$ [6] within a given genotype. Moreover, the mean number of mutations in variable region 3 (V3) plus its upstream flanking region of NS5A [amino acid 2334-2379, referred to as IFN/RBV resistance-determining region (IRRDR)] is significantly higher in $\mathrm{HCV}$ isolates obtained from patients who later achieve SVR by PEG-IFN/RBV than in those from nonSVR patients. On-treatment factors are mainly related to viral kinetics within the first few weeks of treatment [7].

In the current study, with the aim of investigating whether SVR and non-SVR can be distinguished by viral factors such as IRRDR and by on-treatment factors through new indices such as the rebound index (RI), we calculated the first RI (RI-1st; the viral load at week 1 divided by the viral load at $24 \mathrm{~h}$ ) and the second RI (RI-2nd; the viral load at week 2 divided by the viral load at $24 \mathrm{~h}$ ), as proposed by Nomura et al. [8].

\section{Patients and Methods}

The 42 patients included in this study, who all demonstrated high viral loads ( $>100 \mathrm{KIU} / \mathrm{ml}$ ) of serum HCV RNA of genotype $1 \mathrm{~b}$, had been diagnosed with $\mathrm{CHC}$ on the basis of abnormal serum alanine aminotransferase persisting for at least 6 months, and of positive HCV RNA assessed by RT-PCR. None of the patients was positive for hepatitis B surface antigen or other liver diseases (autoimmune hepatitis, alcoholic liver disease). All the patients received a regimen of PEG-IFN $\alpha$-2b (peginterferon alpha-2b; PegIntron; Schering-Plough, Kenilworth, N.J., USA) $(1.5 \mu \mathrm{g} / \mathrm{kg} /$ week, subcutaneously) in combination with RBV (ribavirin; Rebetol; Schering-Plough) 600-1,000 mg/day for 48 weeks. RBV was administered at a dose of $600 \mathrm{mg} /$ day (3 capsules) to patients weighing $<60 \mathrm{~kg}, 800 \mathrm{mg} /$ day (4 capsules) to those weighing $<80 \mathrm{~kg}$ and $1,000 \mathrm{mg} /$ day ( 5 capsules) to those weighing $\geq 80 \mathrm{~kg}$.

The efficacy of the combination therapy was evaluated by HCV RNA negativity determined by qualitative RT-PCR analysis at the end of therapy (end of therapy response) and 6 months after the completion of therapy (SVR). The amount of HCV RNA was also measured quantitatively by RT-PCR (Amplicor HCV monitor v. 2.0; Roche) before therapy. The lower detection limit of the assay was $5 \mathrm{KIU} / \mathrm{ml}$. Samples collected during and after therapy were also determined by qualitative RT-PCR (Amplicor; Roche), which has a higher sensitivity than quantitative analysis, and the results were labeled as positive or negative. The lower limit of the assay was $50 \mathrm{IU} / \mathrm{ml}$.

SVR was defined as undetectable serum HCV RNA at 24 weeks after the cessation of treatment, and non-SVR as detectable HCV RNA at 24 weeks after the discontinuation of treatment. Informed consent was obtained from all patients enrolled in the study after thoroughly explaining the aims, risks and benefits of the therapy.

The amount of HCV core antigen was assessed by the IRM assay (Ortho Clinical Diagnostics, Tokyo, Japan), which provides a good correlation between the amount of HCV core antigen and the amount of HCV RNA, as shown in our previous study [9]. The $\mathrm{HCV}$ core antigen was measured on days 0, 1 (24 h), 7 (1 week) and 14 ( 2 weeks) according to the detection limit of $20 \mathrm{fmol} / \mathrm{l} \mathrm{es}-$ tablished by the manufacturer.

RI-1st was defined as the coefficient derived by dividing the viral load of HCV core antigen at week 1 by that at $24 \mathrm{~h}$, and RI2nd was defined as the coefficient derived by dividing the viral load at week 2 by that at $24 \mathrm{~h} \mathrm{[8]}$.

The patients were divided into 3 groups based on RI-1st and RI-2nd: group A (RI-1st $\leq 1.0)$, group B (RI-1st $>1.0$ and RI-2nd $<0.7)$ and group $\mathrm{C}(\mathrm{RI}-1$ st $>1.0$ and RI-2nd $\geq 0.7)$.

NS5A sequence analysis (IRRDR) was performed as described [4]. Briefly, the sequences of the amplified fragments were determined by direct sequencing without subcloning with the use of a Big Dye Deoxy Terminator cycle sequencing kit and an ABI 337 DNA sequencer (Applied Biosystems, Japan). The aa sequences were deduced and aligned with Genetyx Win software v. 7.0 (Genetyx Corp., Tokyo, Japan). Numbering of aa throughout the manuscript is according to the polyprotein of $\mathrm{HCV}$ genotype $1 \mathrm{~b}$ prototype HCV-J.

\section{Statistical Analysis}

Differences between the groups were assessed by the $\chi^{2}$ test, Fisher's exact test or Student's t test, the Mann-Whitney test and the Kruskal-Wallis test. $\mathrm{p}<0.05$ was considered statistically significant.

\section{Results}

Of the 42 patients treated with combination therapy, 19 (45.2\%) achieved SVR and 23 (54.8\%) were still HCV RNA positive (non-SVR) 6 months after therapy. No significant differences were observed in patient characteristics between SVR and non-SVR, except in platelet counts and the degree of fibrosis (table 1), or among the RI-A, -B and $-\mathrm{C}$ groups (table 2).

The SVR rate was $71.4 \%(10 / 14), 46.2 \%(6 / 13)$ and $20.0 \%(3 / 15)$ in the RI-A, -B and -C groups, respectively, with a significant difference between the RI-A and -C groups ( $p=0.005$ ), but not significant between the RI-A and $-\mathrm{B}$ groups and the RI-B and $-\mathrm{C}$ groups (fig. 1). In the 14 patients of the RI-A group, HCV RNA turned negative 
Table 1. Host-dependent, virus-related profile by response (SVR and non-SVR)

\begin{tabular}{lccc}
\hline & SVR & Non-SVR & p value \\
\hline Gender (M/F), $\mathrm{n}$ & $11 / 8$ & $13 / 10$ & NS \\
Age, years & $56.7 \pm 8.8$ & $59.3 \pm 10.5$ & NS \\
HCV RNA level, KIU/ml & $1,685 \pm 1,477$ & $1,660 \pm 1,363$ & NS \\
HCV core antigen, fmol/l & $7,044 \pm 6,763$ & $9,343 \pm 12,563$ & NS \\
Body weight, kg & $59.9 \pm 11.5$ & $59.8 \pm 13.6$ & NS \\
Treatment history $($ retreatment/naïve) & $6 / 13$ & $13 / 10$ & NS \\
Platelet count $\left(\times 10^{4} / \mathrm{mm}^{3}\right)$ & $18.7 \pm 4.4$ & $14.8 \pm 5.4$ & 0.02 \\
F0, 1/F2, 3 & $12 / 2$ & $5 / 10$ & 0.004 \\
\hline
\end{tabular}

Table 2. Host-dependent, virus-related profile by response (RI-A, -B and -C groups)

\begin{tabular}{lcccc}
\hline & RI-A & RI-B & RI-C & p value \\
\hline Gender (M/F), n & $7 / 7$ & $9 / 4$ & $8 / 7$ & NS \\
Age, years & $60.0 \pm 5.9$ & $58.5 \pm 9.4$ & $56.1 \pm 12.8$ & NS \\
HCV RNA level, KIU/ml & $1,401 \pm 1,014$ & $2,053 \pm 1,286$ & $1,593 \pm 1,772$ & NS \\
HCV core antigen, fmol/l & $6,084 \pm 5,106$ & $7,674 \pm 5,038$ & $11,000 \pm 15,837$ & NS \\
Body weight, kg & $62.1 \pm 16.6$ & $59.5 \pm 10.4$ & $58.2 \pm 10.1$ & NS \\
Treatment history $($ retreatment/naïve) & $3 / 11$ & $7 / 6$ & $9 / 6$ & NS \\
Platelet count $\left(\times 10^{4} / \mathrm{mm}^{3}\right)$ & $15.3 \pm 3.5$ & $18.3 \pm 5.9$ & $16.3 \pm 6.0$ & NS \\
F0, 1/F2, 3 & $7 / 3$ & $5 / 4$ & $5 / 5$ & NS \\
\hline
\end{tabular}

Table 3. SVR rate between IRRDR $\leq 5$ and IRRDR $\leq 6$ in RI-A, $-B$ and - C groups

\begin{tabular}{|c|c|c|c|c|c|c|}
\hline & \multicolumn{2}{|l|}{ RI-A } & \multicolumn{2}{|l|}{ RI-B } & \multicolumn{2}{|l|}{ RI-C } \\
\hline & $\begin{array}{l}\text { IRRDR } \\
\leq 5\end{array}$ & $\begin{array}{l}\text { IRRDR } \\
\geq 6\end{array}$ & $\begin{array}{l}\text { IRRDR } \\
\leq 5\end{array}$ & $\begin{array}{l}\text { IRRDR } \\
\geq 6\end{array}$ & $\begin{array}{l}\text { IRRDR } \\
\leq 5\end{array}$ & $\begin{array}{l}\text { IRRDR } \\
\geq 6\end{array}$ \\
\hline SVR & 3 & 7 & 2 & 4 & 1 & 2 \\
\hline Non-SVR & 3 & 1 & 5 & 2 & 12 & 0 \\
\hline SVR rate, $\%$ & 50.0 & 87.5 & 28.6 & 66.7 & 7.7 & 100 \\
\hline \multirow[t]{2}{*}{$\mathrm{p}$ value } & \multicolumn{2}{|c|}{ NS } & \multicolumn{2}{|c|}{ NS } & \multicolumn{2}{|c|}{0.0024} \\
\hline & \multicolumn{6}{|c|}{0.0003} \\
\hline
\end{tabular}

by week 4 in 3 patients, week 8 in 5 patients, week 12 in 5 patients and was positive in 1 patient throughout the treatment. In the 13 patients of the RI-B group, HCV RNA was negative by week 4 in 1 patient, week 8 in 2 patients, week 12 in 4 patients, at and after week 16 in 5 patients and remained positive throughout the treatment in 1 patient. In the 15 patients of the RI-C group, $\mathrm{HCV}$ RNA was negative by week 12 in 1 patient, on and after week 16 in 6 patients and remained positive throughout the treatment in 8 patients (fig. 2).
The SVR rate was $81.3 \%(13 / 16)$ in the group with $\geq 6$ mutations in IRRDR, and $23.1 \%(6 / 26)$ in those with $\leq 5$ (fig. 3), with a significant difference between the 2 groups $(\mathrm{p}=0.0002)$.

By combining RI and IRRDR, the SVR rate was $87.5 \%$ (7/8) in the RI-A group (IRRDR $\geq 6)$ and $7.7 \%(1 / 13)$ in the RI-C group (IRRDR $\leq 5$ ) (table 3), with a significant difference between the 2 groups $(\mathrm{p}=0.0003)$. 


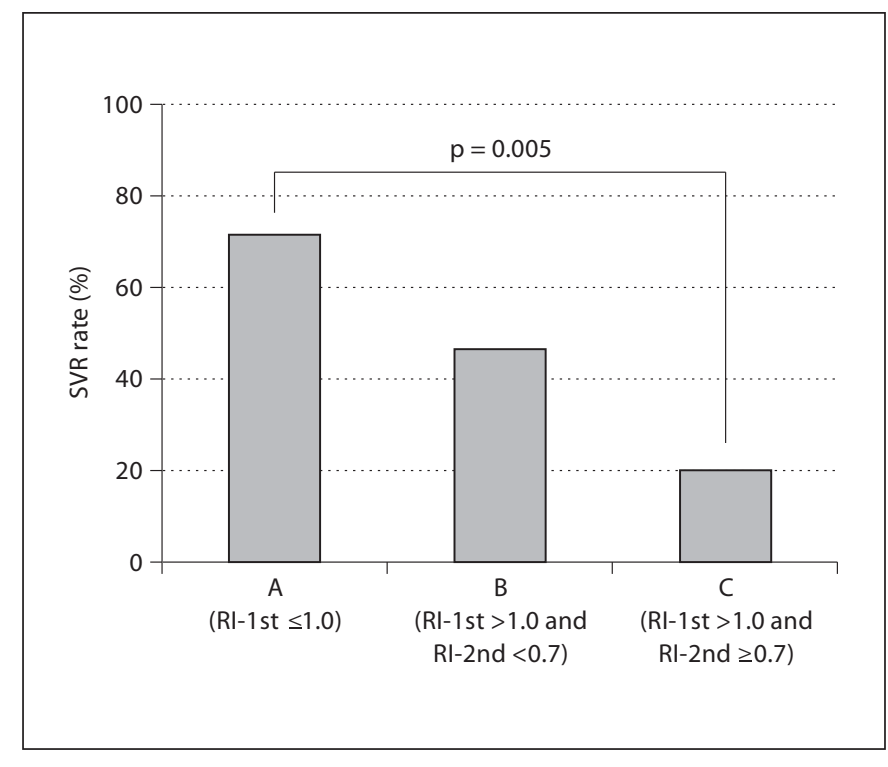

Fig. 1. SVR rate in RI-A, -B and -C groups. The overall SVR rate was $71.4,46.2$ and $20.0 \%$, respectively. Significant difference in SVR rate is indicated.

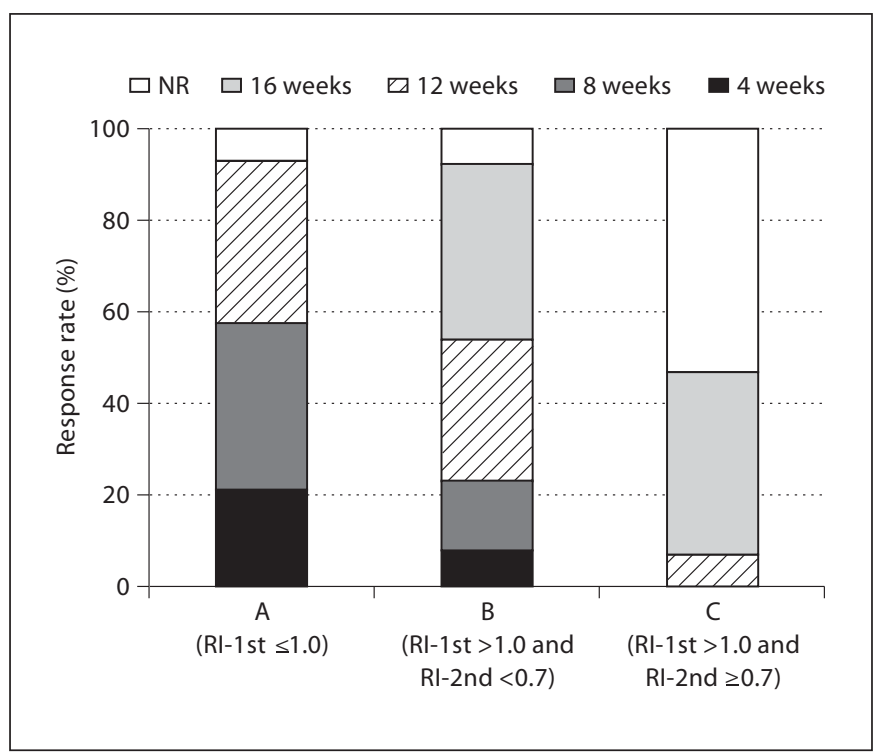

Fig. 2. Relation between response time and virus dynamics. In the 14 patients of the RI-A group, HCV RNA turned negative by week 4 in 3 patients, week 8 in 5 patients, week 12 in 5 patients and remained positive throughout the treatment in 1 patient. In the 13 patients of the RI-B group, HCV RNA was negative by week 4 in 1 patient, week 8 in 2 patients, week 12 in 4 patients, at and after week 16 in 5 patients and remained positive throughout the treatment in 1 patient. In the 15 patients of the RI-C group, HCV RNA was negative by week 12 in 1 patient, at and after week 16 in 6 patients and remained positive throughout the treatment in 8 patients.

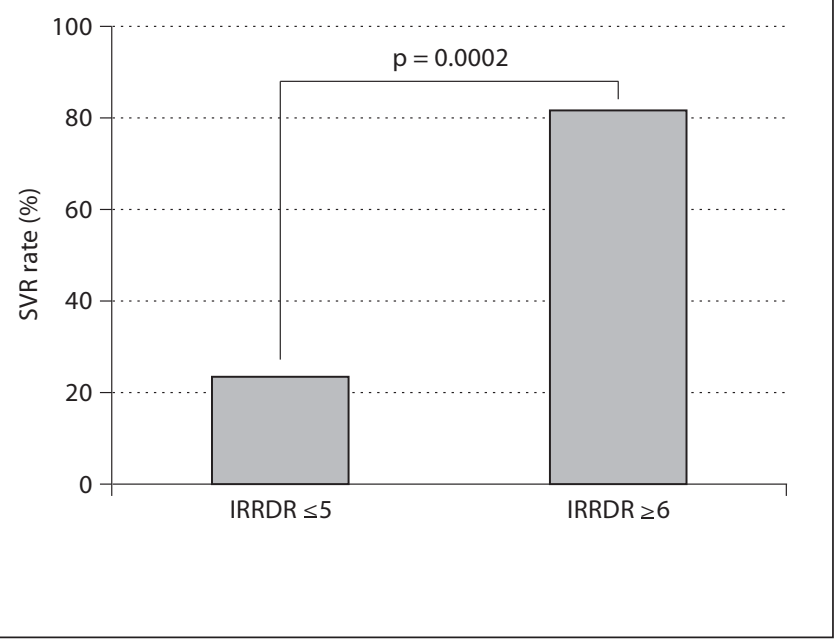

Fig. 3. SVR rate and IRRDR number. The SVR rate was $23.1 \%$ in IRRDR $\leq 5$ and $81.3 \%$ in IRRDR $\geq 6$, which was significantly different.

\section{Discussion}

The importance of early virological response (EVR; signifying HCV RNA negative at 12 weeks) has been emphasized in predicting SVR and non-SVR in CHC patients undergoing IFN treatment; those not reaching EVR do not respond to further therapy. Discontinuation of treatment in patients not reaching EVR would reduce drug costs by more than $20 \%$; consequently, early confirmation of viral reduction after initiating antiviral therapy for $\mathrm{CHC}$ is worth investigating [10].

Treatment with IFN induces a decline in HCV RNA levels that can be mathematically measured in 2 phases. The decline in the first phase, usually measured at 24 or $48 \mathrm{~h}$, probably reflects direct inhibition of intracellular production and release of HCV [11], with IFN efficacy ranging from about 70\% (approx. 0.7 log units) for standard IFN (given 3 times a week) to more than 90\% (1 log unit) for high daily doses of standard IFN or PEG-IFN (given once a week) $[12,13]$. The decline in the second phase, beginning after $24-48 \mathrm{~h}$, is slower and more variable than that in the first phase, and is thought to reflect continued inhibition of replication and the gradual elimination of virus-infected cells [11]. The decay in the first phase has little correlation with the IFN dose, but is more rapid with PEG-IFN than with standard IFN preparations [10]. 
Lowering HCV RNA during the first phase is essential for efficient elimination of HCV during the second phase. Decreases in HCV RNA titers within the first 24-48 h after the start of IFN would, therefore, be a dependable estimate of antiviral efficacy $[12,13]$.

Early viral kinetics, determined up to week 2, are believed to express the therapeutic effect of PEG-IFN. The concentration of PEG-IFN $\alpha-2 b$ in serum peaks after $24 \mathrm{~h}$, then declines gradually $[14,15]$. The viral load is thus reduced by $24 \mathrm{~h}$ but increases in week $1[16,17]$; with a large dose of PEG-IFN at each administration, it decreases markedly at $24 \mathrm{~h}$ but then increases in week 1 regardless of the dose. In the responder group, however, the viral load continues to decline each week thereafter [17].

In this study, we used new indices proposed by Nomura et al. [8]: RI-1st and RI-2nd calculated from early viral kinetics. RI-1st was defined as the coefficient derived by dividing the viral load of HCV core antigen at week 1 by that at $24 \mathrm{~h}$, and the RI-2nd was defined as the coefficient derived by dividing the viral load at week 2 by that at $24 \mathrm{~h}$. In the SVR group, a number of patients demonstrated no increase in the viral load at week 1 . Patients with a high RI-2nd were regarded as poor responders or non-responders to PEG-IFN. The RI-2nd of those other than non-responders was below 0.7 ; therefore, 0.7 was adopted as the reference value for RI-2nd, and the patients were divided into 3 groups based on RI-1st and RI2nd: the RI-A group (RI-1st $\leq 1.0$ ), the RI-B group (RI-1st $>1.0$ and RI-2nd $<0.7$ ) and the RI-C group (RI-1st $>1.0$ and RI-2nd $\geq 0.7$ ). The SVR rate of the RI-A, RI-B and RI-C groups was $71.4 \%(10 / 14), 46.2 \%(6 / 13)$ and $20 \%$ $(2 / 10)$, respectively $(\mathrm{p}=0.005$ between the RI-A group and the RI-C group). RIs are also associated with the early clearance of HCV RNA that is related to SVR.

In the RI-A group $21.4 \%(3 / 14), 35.7 \%$ (5/14) and 35.7\% (5/14) became HCV RNA negative by weeks 4,8 and 12 , respectively. In the RI-B group 7.7\% (1/13), 15.4\% (2/13), $30.8 \%(4 / 13)$ and $38.5 \%(5 / 13)$ became HCV RNA negative by weeks $4,8,12$, and at and after week 16 , respectively. In the RI-C group 6.7\% (1/15) and 40.0\% (6/15) became HCV RNA negative by week 12 , and at and after week 16 , respectively. It is believed that the simplified RI1st and RI-2nd are evidential indices for determining the therapeutic efficacy of PEG-IFN/RBV treatment.

We have previously reported that the high degree of sequence variation in IRRDR (IRRDR $\geq 6$ ) significantly correlates with SVR, whereas the low degree of sequence variation in this region (IRRDR $\leq 5$ ) correlates with nonSVR [4]. A significant correlation between the rapid reduction of HCV core antigen titers and the degree of se- quence variation in IRRDR has been observed. This, in particular, suggests a possible influence of IRRDR $\geq 6$ on HCV replication kinetics during IFN-based therapy, especially that the direct effect of IFN begins a few hours after the first dose.

In this study, the SVR rate was $81.2 \%(13 / 16)$ with IRRDR $\geq 6$ and $23.1 \%(6 / 26)$ with IRRDR $\leq 5(p=0.0002)$, strongly suggesting that IRRDR $\geq 6$ would be a useful marker for the prediction of SVR.

By combining RI and IRRDR as a predicting factor, the SVR rate was $87.5 \%(7 / 8)$ in the RI-A group (RI-1st $\leq 1.0$ ) with IRRDR $\geq 6$, signifying that about $90 \%$ of these patients turned SVR and were, thus, believed to be very good responders. An SVR rate of 7.7\% (1/13) was obtained in the RI-C group with IRRDR $\leq 5(\mathrm{p}=0.0003)$.

In conclusion, we propose that IRRDR combined with RIs is the most sensitive predictive factor for SVR and non-SVR. With the aid of RIs and IRRDR, a more effective PEG-IFN/RBV treatment could be within reach. A more detailed investigation with a larger number of subjects is needed to confirm the current results in patients given PEG-IFN/RBV combination therapy.

\section{Acknowledgment}

We are indebted to Yoshiko Kawamura for assistance in the preparation of the manuscript.

\section{Disclosure Statement}

No conflict of interest exists.

References

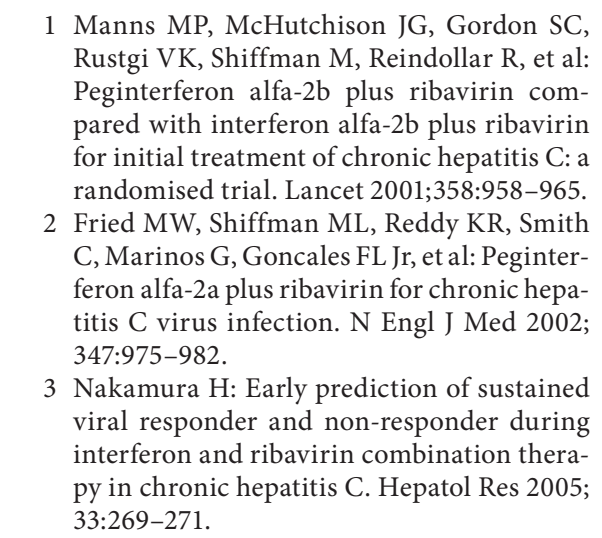

Intervirology 2010;53:49-54 
4 El-Shamy A, Nagano-Fujii M, Sasase N, Imoto $\mathrm{S}, \mathrm{Kim}$ SR, Hotta $\mathrm{H}$ : Sequence variation in hepatitis $\mathrm{C}$ virus nonstructural protein $5 \mathrm{~A}$ predicts clinical outcome of pegylated interferon/ribavirin combination therapy. Hepatology 2008;48:38-47.

$\checkmark 5$ Enomoto N, Sakuma I, Asahina Y, Kurosaki M, Murakami T, Yamamoto C, Ogura Y, Izumi N, Marumo F, Sato C: Mutations in the nonstructural protein $5 \mathrm{~A}$ gene and response to interferon in patients with chronic hepatitis C virus 1b infection. N Engl J Med 1996; 334:77-81.

6 Akuta N, Suzuki S, Kawamura Y, Yatsuji H, Sezaki H, Suzuki Y, Hosaka T, Kobayashi M, Kobayashi M, Arase Y, Ikeda K, Miyakawa Y, Kumada H: Prediction of response to pegylated interferon and ribavirin in hepatitis $\mathrm{C}$ by polymorphism in the viral core protein and very early dynamics of viremia. Intervirology 2007;50:361-368.

$\checkmark 7$ Ferenci P: Predictors of response to therapy for chronic hepatitis C. Semin Liver Dis. 2004;24:S25-S31.

$\checkmark 8$ Nomura H, Miyagi Y, Tanimoto H, Higashi $\mathrm{M}$, Ishibashi $\mathrm{H}$ : Effective prediction of outcome of combination therapy with pegylated interferon alpha $2 \mathrm{~b}$ plus ribavirin in Japanese patients with genotype-1 chronic hepatitis $\mathrm{C}$ using early viral kinetics and new indices. J Gastroenterol 2009;44:338-345. $\checkmark 9$ Sasase N, Kim SR, Kim KI, Taniguchi M, Imoto S, Hotta H, Shouji I, El-Shamy A, Kawada N, Kudo M, Hayashi Y: Usefulness of a new immunoradiometric assay of HCV core antigen to predict virological response during PEG-IFN/RBV combination therapy for chronic hepatitis with high viral load of serum HCV RNA genotype 1b. Intervirology 2008;51:S70-S75.

10 Davis GL: Monitoring of viral levels during therapy of hepatitis C. Hepatology 2002;36: S145-S151.

11 Neumann AU, Lam NP, Dahari H, Gretch DR, Wiley TE, Layden TJ, Perelson AS: Hepatitis $C$ viral dynamics in vivo and the antiviral efficacy of interferon- $\alpha$ therapy. Science 1998;282:103-107.

12 Lam NP, Neumann AU, Gretch DR, Wiley TE, Perelson AS, Layden TJ: Dose-dependent acute clearance of hepatitis $\mathrm{C}$ genotype 1 virus with interferon alfa. Hepatology 1997;26:226-231.

13 Zeuzem S, Herrmann E, Lee JH, Fricke J, Neumann AU, Modi M, Colucci G, Roth WK: Viral kinetics in patients with chronic hepatitis $\mathrm{C}$ treated with standard or peginterferon alfa-2a. Gastroenterology 2001;120: 1438-1447.
4 Silva M, Poo J, Wagner F, Jackson M, Cutler $D$, Grace M, et al: A randomized trial to compare the pharmacokinetic, pharmacodynamic, and antiviral effects of peginterferon alfa- $2 \mathrm{~b}$ and peginterferon alfa- $2 \mathrm{a}$ in patients with chronic hepatitis C (COMPARE). J Hepatol 2006;45:204-213.

-15 Asahina Y, Izumi N, Umeda N, Hosokawa T, Ueda K, Doi F, et al: Pharmacokinetics and enhanced PKR response in patients with chronic hepatitis $C$ treated with pegylated interferon alpha-2b and ribavirin. J Viral Hepat 2007;14:396-403.

16 Izumi N, Asahina Y, Kurosaki M, Uchihara $\mathrm{M}$, Nishimura $\mathrm{Y}$, Inoue $\mathrm{K}$, et al: A comparison of the exponential decay slope between PEG-IFN alfa-2b/ribavirin and IFN alfa-2b/ ribavirin combination therapy in patients with chronic hepatitis $\mathrm{C}$ genotype $\mathrm{lb}$ infection and a high viral load. Intervirology 2004;47:102-107.

17 Buti M, Sanchez-Avila F, Lurie Y, Stalgis C, Valdes A, Martell M, et al: Viral kinetics in genotype 1 chronic hepatitis $\mathrm{C}$ patients during therapy with 2 different doses of peginterferon alfa-2b plus ribavirin. Hepatology 2002;35:930-936. 